\title{
Job-demand for learning and job-related learning: the mediating effect of job performance improvement initiatives
}

Please indicate the corresponding author. Thank you.
Please provide biographical

notes of each author

(maximum of

150 words

only). Thank

you.

\section{Mark Kong Chew Loon and Gian Casimir}

Newcastle Graduate School of Business

University of Newcastle, NSW 2308, Australia

Fax: (+61 2) 49217398

E-mail: mloonkc@gmail.com

E-mail: gian.casimir@newcastle.edu.au

*Corresponding author

\section{Timothy Bartram}

School of Business, La Trobe University

Victoria 3086, Australia

Fax: (+61 3) 94795837

E-mail: t.bartram@latrobe.edu.au

\begin{abstract}
This study examined whether job-performance-improvementinitiatives mediate the relationship between individuals' job-demand for learning and job-related learning. Data were obtained from 115 full-time employees in a diverse range of occupations. A partial least squares analysis revealed that job-performance-improvement-initiatives mediate partially the effects of job-demand for learning on job-related learning. Several implications for future research and policy are drawn from the findings.
\end{abstract}

Keywords: job-demand for learning; job performance improvement initiative; job-related learning.

Reference to this paper should be made as follows: Loon, M.K.C., Casimir, G. and Bartram, T. (xxxx) 'Job-demand for learning and job-related learning: the mediating effect of job performance improvement initiatives', Int. J. Human Resources Development and Management, Vol. X, No. Y, pp.000-000.

Biographical notes: Mark Kong Chew Loon is a DBA student from the University of Newcastle.

Gian Casimir is a Lecturer at Newcastle Graduate School of Business, University of Newcastle. He received his PhD in leadership from the University of Newcastle. His research interests include quantitative methods, leadership and cross-cultural management.

Dr Timothy Bartram is a Senior Lecturer in the School of Business, La Trobe University. He received his $\mathrm{PhD}$ in human resource management from $\mathrm{La}$ Trobe University, Australia. His research interests include the practice of HRM in unionised settings, HRM in the public health sector and high performance work systems. job-demand or job demand?

job-

performanceimprovementinitiatives or job performance improvement initiatives?

(with or without hyphen)? 


\section{Introduction}

Increased dynamism in the business environment is a cause of turbulence in the workplace (Boxall and Purcell, 2003). Learning in organisations has become more prominent as a research topic as competition between organisations has increased considerably in the last few decades (Arthur and Huntley, 2005; Simonin, 1997). The re-emergence of the importance of learning is due to the recognition that expedient learning is an effective mean for organisations to attain competitive advantage (Agyris, 1999). The competitive and volatile environment within which organisations operate is prompting senior management to take a greater interest in the development of the organisation's human resources (Garavan, 1991). Learning helps to close the gap between current competencies and desired future competencies. Learning can be thought of as a relatively permanent change in behaviour or behaviour potential that results from one's experiences (Delahaye, 2005).

Given the importance of employee learning and its crucial role in improving individual (Agyris, 1999) and organisational performance (Garavan, 1991) this study examines an under-developed aspect within the management literature of whether job-performance-improvement-initiatives mediate the relationship between individuals' job-demand for learning and job-related learning.

\section{Job-demand for learning}

A job can be described in terms of explicit tasks and roles that must be undertaken and fulfilled in order to meet specific objectives that eventually contribute to group and organisational goals (Torrington and Hall, 1998). Jobs vary in terms of the demands or expectations that they place on employees and these demands can range, for example, from managing a database to managing a whole organisation. In this study, the term 'job' is defined broadly as a process with specific tasks for meeting objectives. Hence, this definition is relevant to everyone in a formal organisational context and also to others such as entrepreneurs, who do not have jobs per se but have processes to undertake and responsibilities to meet that will ultimately lead to attaining objectives.

Job-demand for learning refers to challenges faced in jobs caused by changes in requisite knowledge, roles, responsibilities or functions due to factors such as technological or processual changes or to a change in job (e.g., promotion or lateral move). Job demands vary according to the nature tasks in individuals' job. However, Fry and Kolb (1979) argued that there are similarities in the general demands of most jobs. The four types of job demands on employees are affective, perceptual, symbolic and behavioural.

Affective job demand involves a wide range of interpersonal skills required to perform a job. Many jobs require interaction with colleagues, clients, superiors and subordinates. Such interactions are important as the completion of tasks and the meeting of objectives can only be achieved with and through others (Sims, 1983). Examples of such jobs include sales and counsellors. The mastery of people skills in interacting and managing people are a type of job demand and require interpersonal intelligence (Vincent and Ross, 2001). 
Perceptual job-demand involves the observation, analysis and synthesis of information in determining cause-and-effect dynamics in providing the most appropriate solutions (Sims, 1983). As its term indicates, perceptual job-demand requires the job-holder to clearly perceive the problem in taking remedial or pre-emptive action. For example, a strategic planner in a bank observe trends in the external environment and collect data before extrapolating the future direction of the industry and eventually recommending actions that the bank should take. Jobs that demand such orientation include strategist and research scientist. The perceptual orientation demands logical-mathematical type of intelligence (Vincent and Ross, 2001).

Symbolic job-demand is the mastery and application of technical skills. It differs from perceptual job-demand; as it less conceptual and largely deals with technical problem-solving such as those faced on a daily basis (Sims, 1983). The types of jobs that require symbolic orientation include engineering and medical doctors. The symbolic orientation demands both logical-mathematical and visual-spatial intelligences (Vincent and Ross, 2001).

Behavioural job-demand emphasises the presence of the job-holder in planning, coordinating and controlling work. The behavioural orientation requires the physical intervention of the job-holder in ensuring that job tasks are completed. Examples of such jobs include administrators and project coordinators. Evidently, the behavioural orientation demands a number of intelligences such as logical-mathematical, visual-spatial and interpersonal intelligences (Vincent and Ross, 2001).

Sims (1983) argued that although the four orientations job-demands are arbitrary, it is indicative of the type of job-demands that are consistently present in almost all types of jobs. The emphasis of each orientation may differ, dependent on specific job specification, organisational requirements and job-holder's position (e.g., managerial and non-managerial).

In addressing the limitation of Fry and Kolb's conceptualisation of job-demands, the perspective of job dynamism can be adopted. An assumption of job dynamism is that job-demand is not static. It is arguably the case that most jobs place demands on employees to learn new skills and/or ways of doing their work. The more dynamic a job is, the more demand it places on individuals to learn. Job-demand for learning is a construct that indicates the pace and intensity of change of a job that corresponds to the rate and level of learning required to effectively perform the job. Measures of job-demand for learning from a job dynamism perspective include the rate of change in jobs and rising complexities due to increasing tasks and its interdependence.

\section{Job-demand for learning and job-related learning}

"Learning is the process of linking, expanding, and improving data, information, knowledge and wisdom" (Bierly et al., 2000, p.597). In the context of job-related learning, Bierly et al.'s (2000) definition refers to factors that facilitate the enhancement of skills, acquirement of new knowledge, and increment in capabilities and competencies that allow incumbents to do their jobs more efficiently and effectively. Learning closes the gap between required competencies and job-holders' current competencies. Furthermore, according to Antonacopoulou and FitzGerald (1996), a competency consists of the virtues unique to each individual, which are expressed in the process of interacting 
with others in a given context. This definition does not limit competency to specific knowledge and skills, instead it embraces attitudes, perceptions and emphasises that competence is defined and redefined as personal and situational.

Learning manifests itself cognitively and/or behaviourally. Measuring learning from a cognitive perspective is challenging, as learning can be intangible and thus unobservable. However, knowledge, as the end-state of pattern recognition, is a useful measure when individuals recognise its presence. Changes in behaviour are the most common denominator in recognising that learning has taken place (Lahey, 2004). Positive changes in behaviours, such as learning to do perform the job better and acquirement of new skills, are important indicators of job-related learning.

Job-related learning encompasses the acquirement of both functional and specific competencies. Functional competencies are related to job-functions (e.g., tasks) and roles (e.g., responsibilities), and the understanding of its interaction with other job roles. Such competencies are non-transferable as they are organisational-specific. Specific competencies are attributes of the individual that aids them to perform successfully and are transferable as they are intrinsic to the individual (Devisch, 1998).

Interaction between the individual (i.e., the learner) and the learning environment (i.e., the job) are intimate (Sims, 1983). The rate of learning is a function of tasks within a job. Particularly the challenges present in the job and the opportunities of growth (van der Heijden, 2001). In contrast, static and unchallenging jobs provide inadequate motivation for learning. Unchallenging jobs do not stimulate individuals to think of new and better ways to perform. Routines inculcate passive behaviour that may circumvent any type of learning (van der Sluis-den Dikken and Hoeksema, 2001).

Individuals are compelled to learn if challenges in jobs are present (Nyhan et al., 2004). Job-demand for learning is an external factor that stimulates job-related learning (Boyatzis, 1982) as it compels the employee to adapt to the requirements of the job. Job-demand for learning spurs individuals to continuously minimise the gap between their current level of competency and the level of competency required to effectively performing their jobs (Loogma, 2003).

Van Woerkom (2003) argued that work motivates individuals when it challenges and engages individuals at a higher level of commitment as most learning occurs on the job. Ellstrom (2003) recommended that the characteristics of developmental work that is required to support learning includes work that has a high degree of complexity, high opportunities to use task relevant knowledge, opportunities for feedback, evaluation and reflection, participation in work design, and formal participation in resolving problems and overall developmental programmes and activities. Challenging jobs will inculcate learning in an individual's job.

H1 Job-demand for learning will correlate positively to job-related learning.

\section{Job performance improvement initiatives}

Job performance improvement initiatives are internal motivations of individuals in exploring new and better ways in performing their jobs. Most improvement initiatives are continuous programmes at the organisational level (Bhuiyan and Baghel, 2005). However, individuals should also be given recognition for their efforts in improving job 
Please verify highlighted text. performance. Although individuals' efforts may be ad hoc and less structured compared to the organisations, job performance improvement initiatives of individuals can be both incremental and radical (Bhuiyan and Baghel, 2005).

Job performance improvement initiatives do not necessarily indicate that performance has improved but it does indicate that steps have been taken by the individual to perform better on their job. The processual view of the construct suggests that the individual undertakes activities and tasks beyond their current job-related routines. The individuals' behaviours transcend to the next level of learning from mere reactive adaptation to their jobs to approach their jobs via active experiment with the objective of improving the job performance (Boydell, 1990).

As job-demand for learning increases, individuals are compelled to seek new and better ways to improve their job performance. Individuals' competencies and the job demands must commensurate as the lack of commensurability will cause dissonance (Sims, 1983). As job-demands increase, job performance improvement initiatives must also intensify to bring equilibrium to job-demands and job-related learning, as learning should narrow the disparity between growing job-demands and present competencies. In other words, job performance improvement initiative is a product of job-demand for learning and is a cause of job-related learning.

\section{H2 Job performance improvement initiatives will mediate the relationship between} job-demand for learning and job-related learning.

\section{Method}

\subsection{Participants}

One hundred and fifteen full-time employees participated in this study. The average age of the participants was 31.2 years (s.d. $=7.5$ years). The sample comprised of 58 females and 57 males who worked in a diverse range of occupational fields (e.g., administration, engineering, information technology, and marketing). Twenty-six percent of the participants held post-graduate degrees (i.e., Masters or doctorate), 36\% held Bachelors Degrees, and the remainder held diplomas or had only completed high school education. The average tenure of participants in their respective organisation was 4.7 years (s.d. $=5.7$ years), while the average number of years that the participants had worked in their current jobs was 2.8 years (s.d. $=3.6$ years). Thirty-four percent of the participants held executive or senior management positions, $51 \%$ held middle or lower management positions, and $15 \%$ held non-managerial positions.

\subsection{Measures}

The scales for job-demand for learning, job performance improvement initiatives and job-related learning were developed for this research. The items used for these scales are presented in the Appendix. The items developed to tap the job-demand for learning variable adopts the perspective of job dynamism. Dynamic jobs are not static and imposes pressure on employees due to the pace and intensity of change. Job-demand for learning can be measured from its rapidity and constancy. Rapid changes in jobs are the speed of change while constant change reflects the frequency of change. Each of these 
elements places pressure on individuals to cope with changes by learning new requirements as a result of the changes. The increasing complexity of work is characterised by the element of rising number of tasks and responsibilities. These are significant changes that make the job more arduous and challenging, which is expected to cause individuals to learn more so that they can manage increased workloads.

Job-performance improvement initiatives are measured from the participants' past action in seeking ways to improve their job performance. The actions of participants to seek better and new ways to improve their job performance tap the job-performance improvement initiatives taken by the participants. The phrase 'in the last six months' was included at the start of each item to ensure that the participants' response to the variable reflected recent actions and initiatives.

Job-related learning is measured from two dimension; cognition and behaviour. The dimension representing cognition is inferred by individuals acquiring new knowledge, perspectives and skills. In addition, the cognitive dimension of job-related learning manifests itself when individuals are able to identify better and new ways to do their jobs. Individuals are able to recognise and understand patterns and relationships that are related to their tasks and roles. The cognitive rationale used in this study is synonymous with higher order heuristics as individuals learn how to learn and learn how to teach themselves in ways that suit them best.

The behavioural dimension of job-related learning is observable when individuals are seen to actively enquire about new and better ways to do their jobs so as to enhance their performance. The behaviour of enquiry is a learning activity to solve problems by actively integrating knowledge from themselves and others. In addition, they also perceive themselves applying new and better skills. The phrase 'in the last six months' was included at the start of each item to ensure that the participants' response to the variable reflected recent learning and to correspond with job-performance improvement initiatives. A five-point Likert scale is consistently used in measuring all three constructs. The verbal poles of the five-point Likert scale in a continuum are 'strongly disagree', 'disagree', 'not sure', 'agree' and 'strongly agree'.

\subsection{Procedure}

A package containing a copy of the questionnaire, an information sheet with brief details of the research, and a prepaid return envelope was distributed to human resource managers in each of the selected organisations. This data collection procedure enabled participants to complete the questionnaire at a time and place of their choice and assured them of anonymity as they posted the completed questionnaire directly to the researchers.

\section{Results}

Table 1 contains the means, standard deviations, correlations, and internal reliabilities for the measured variables. Gender correlated negatively with job-demand for learning thereby indicating that males reported higher levels of job-demand for learning than did females. Age and years in the job did not correlate significantly with job-demand for learning. Age, gender, and years in job did not correlated significantly with job-performance improvement initiatives. Gender and years in job correlated significantly with job-related learning. The effects of gender and years in the current job on job-related 
learning were controlled by using standardised residual scores obtained by regressing each of the job-related learning items on gender and years in the current job.

Table 1 Means (s.d.), Correlations, ${ }^{a}$ and Average Variance Extracted ${ }^{\mathrm{b}}$ for the measured variables

\begin{tabular}{lccccccc}
\hline & Mean $($ s.d. $)$ & 1 & 2 & 3 & 4 & 5 & 6 \\
\hline 1 Age & $30.9(8.0)$ & & & & & & \\
2 Gender & - & -0.11 & - & & & & \\
3 Years in job & $2.8(3.6)$ & 0.44 & -0.02 & - & & & \\
4 Job-demand for learning & $3.3(0.7)$ & -0.03 & -0.21 & 0.03 & $(0.55)$ & & \\
5 Job-performance & $3.2(0.6)$ & -0.02 & -0.07 & -0.06 & 0.19 & $(0.76)$ & \\
$\quad$ improvement initiative & & & & & & & \\
6 Job-related learning & $3.4(0.7)$ & -0.08 & 0.27 & -0.17 & 0.20 & 0.35 & $(0.76)$ \\
\hline
\end{tabular}

Notes: $\quad{ }^{a}$ Significance: $r>0.15, p<0.05 ; r>0.22, p<0.01 ; r>0.28, p<0.001$

${ }^{\mathrm{b}}$ The average variance extracted for each scale is presented in parentheses on the diagonal

As seen in Table 1, job-demand for learning correlated positively and significantly to job-related learning: Hypothesis 1 was therefore supported. Furthermore, job-demand for learning correlated significantly and positively to job-performance improvement initiatives whilst job-performance improvement initiatives correlated significantly and positively to job-related learning.

All of the data were obtained from a single source (i.e., employees) at a single point in time using a single method. The covariance between the constructs therefore may be influenced by single-source and common-method biases. A single-component test was conducted on all of the items to examine whether the majority of the covariance between the items could be attributed to common source/method variance. The results from this analysis revealed that the first component accounted for $36.5 \%$ of the total variance in the items thereby indicating that common source/method variance did not explain the majority of the variance in the items.

\section{PLS analyses}

A Partial Least Squares (PLS) analysis was conducted to examine whether job-performance improvement initiatives mediated the relationship between job-demand for learning and job-related learning. PLS was selected to analyse the hypothesised mediation model because PLS does not require assumptions of multivariate normality and is suitable for small samples (Chin, 1998). The bootstrapping procedure in PLS Graph was used to test the significance of the regression coefficients. Bootstrapping involves the random re-sampling of the original dataset for estimating the error of the estimated path coefficients (Chin, 1998).

The convergent and discriminant validity of the measured constructs were examined by calculating the Average Variance Extracted (AVE) for the construct. The AVE represents the average squared loading (i.e., average communality) of the items representing a construct as obtained from the PLS analysis. In order for a measure to have acceptable convergent and discriminant validity, it should have an AVE greater than 
0.5 and share more variance with its items than with other constructs in the model (Chin, 1998).

Table 1 shows that the AVE was greater than 0.5 for all three constructs. Furthermore, for each of the three constructs, the squared correlation coefficient between it and the other two constructs is less than its AVE thereby indicating that all three constructs have acceptable convergent and discriminant validity.

The internal reliability of each scale was calculated using the composite reliability, which is similar to Cronbach's alpha in that it measures internal consistency. The composite reliability index needs to exceed 0.70 in order to indicate satisfactory internal consistency (Hair et al., 1998). The composite reliability for job-demand for learning is 0.78 , for job-performance improvement initiative it is 0.87 , and for job-related learning is 0.91. All of the scales thus have satisfactory composite reliabilities.

Figure 1 depicts the proposed mediation model and contains the findings from the PLS analysis, which revealed that job-performance improvement initiatives mediated partially the effect of job-demand for learning on job-related learning: Hypothesis 2 was therefore partially supported.

Figure 1 PLS results for the mediation model

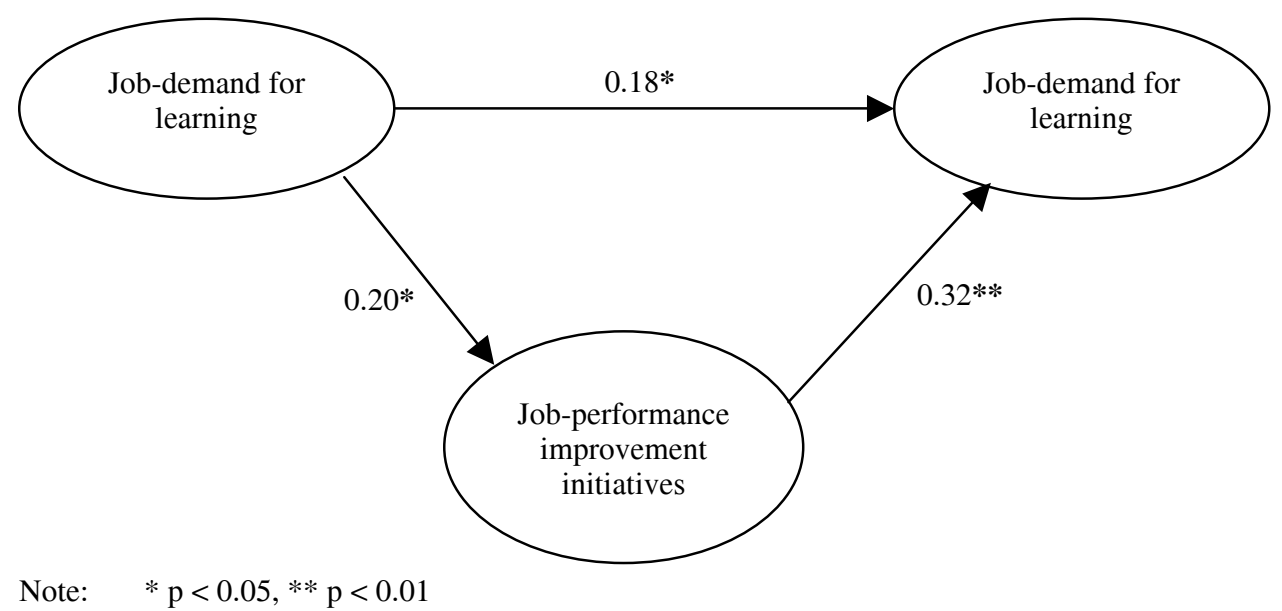

The indirect effect of job-demand for learning on job-related learning via job-performance improvement initiative is 0.064 (i.e., $0.20 \times 0.32$ ). The direct effect of job-demand for learning on job-related learning was divided by the indirect effect to obtain an 'effects ratio', which can be used to compare the relative strengths of the direct effect and the indirect effect. When the effects ratio is greater than 1.0, the direct effect is greater than the indirect effect whereas when the effects ratio is less than 1.0 the direct effect is less than the indirect effect. An effects ratio equal to 1.0 indicates that the direct effect is equal to the indirect effect. The effects ratio is 2.8 (i.e., 0.182/0.064), which indicates that the direct effect is 2.8 times greater than the indirect effect.

The 'variance attributable to path' was calculated by multiplying the standardised regression coefficient for the path by the correlation coefficient of the two variables in the path, as recommended by Fornell and Larcker (1981). The variance explained in job-related learning that is attributable to job-demand for learning is 0.04 (i.e., $0.18 \times 0.20)$ and the variance attributable to job-performance improvement initiative 
is 0.11 (i.e., $0.32 \times 0.35$ ); both of these values exceed the 0.015 criterion recommended by Fornell and Larcker (1981).

\section{Discussion}

The findings reveal that job-demand for learning is correlated positively to job-related learning and thus support the argument that individuals who occupy jobs that placed demands on them to learn new skills and roles need to acquire skills and knowledge to do their jobs effectively. Job-related learning therefore reduces the gap between required and current competencies.

Job-performance improvement initiative mediated partially the effects of job-demand for learning on job-related learning. It makes sense that employees need to take the initiative when it comes to coping with the demands for new skills and knowledge that are placed on them by their jobs. Indeed, it is plausible that an individual will not acquire or improve job-related skills and knowledge despite occupying a job that requires learning new skills and knowledge if the individual is passive about the learning process. Job performance improvement initiatives represent actions that have been taken to improve job performance and thus it is reasonable that such actions, and their underlying motives, facilitate the acquisition of job-related skills and knowledge.

\subsection{Job-design and opportunities for learning}

The job characteristics model provides some rationalisation of job demands. The model's five core job characteristics - high levels of skill variety, task identity, task significance, autonomy, and job feedback (Hackman and Oldman, 1980) - have been shown to consistently predict outcomes such as internal work motivation, job involvement, and job satisfaction (Fried and Ferris, 1987), within the context of having the ability to master tasks and work.

Hackman and Oldman (1980) hypothesis that the design of work to incorporate enriching and challenging tasks, activities and responsibilities are associated with job outcomes such as reduced absenteeism is supported by this study. Van Woerkom (2003) argued that work motivates individuals to learn when it challenges and engages individuals at a higher level of commitment. Job-related learning occur when work challenges people to think and resolve problems by learning from the tasks (i.e., past experiences) and other people around them. Work should be designed to be challenging.

The use of human resource development initiatives such as a combination of structured and unstructured learning strategies to build job-related learning opportunities is an important consideration for management (Delahaye, 2005). More specifically, management may choose to utilise structured learning strategies such as skill session and simulations to instruct employees in programmed, task and relationship knowledge and use unstructured learning strategies for such as mentoring for more complex forms of knowledge generation such as critical thinking and met-abilities (Gagne et al., 2002). Given the growing importance of complex forms of knowledge required by employees in the modern organisation, the use of mentoring is particularly important in stimulating job related learning (Orpen, 1997). Mentoring in organisations can be viewed as a developmental relationship whereby managers provide assistance and support to 
Kram, 2001). The mentoring process can serve both career and learning enhancement (e.g., sponsorship, coaching, exposure and provision of challenging assignments) and psychosocial functions (e.g., acceptance, counselling, emotional support and role modelling) for the mentee.

\subsection{Job-performance improvement initiatives and empowerment}

Learning is a desire-based function (Illeris, 2003; Furth, 1987). However, such desires are not easy to inculcate in adults as adults only learn when they are able to articulate its relevance to their needs (Illeris, 2003). The relevance of learning can be attributed to job-demands placed on adults. The decision to find ways to improve job performance lies with the employees themselves and cannot be decided for them (Illeris, 2003). Job-performance improvement initiatives exhibited by employees need to commensurate with a degree of empowerment.

The construct of empowerment embodies employees taking initiative, embracing risk, stimulating innovation, and coping with uncertainty (Spreitzer, 1995). Empowerment as an enabling process affects both the initiation and the persistence of followers' task-oriented behaviours (Bandura, 1977). Empowerment is a powerful tool that provides employees with the autonomy to learn via action learning i.e., making decisions. Empowerment positively influences learning (Field, 1997). Empowerment is observed as the perceived degree of work-related choices available to individuals and groups, tolerance of failure by experimentation, and support and recognition for personal initiatives (Field, 1997).

\subsection{Limitations and directions for future research}

The cross-sectional design used in this study is a limitation in that it does not allow inferences to be drawn about the causal relationships between job-demand for learning, job-performance improvement initiative, and job-related learning. Future research should consider using a longitudinal design that would better facilitate the drawing of causal inferences.

All of the data collected for this study were obtained from a single source (i.e., the employees) and via a common method (i.e., a questionnaire with Likert scales). Mono-source and common-method biases therefore may have increased both measurement error and/or the correlations amongst the variables measured in this study. Although it is difficult to prove that such biases are not highly influential, the findings from the single-component principal components analysis, the other principal components analyses, and the mediation analysis indicate that mono-source and common-method biases were not substantial in this study.

The conclusion drawn from this study should be applied with prudence as jobs undertaken by individuals are assumed be the individual's chosen profession and has some form of interest in the job to prompt minimum levels of motivation to learn. Jobs that are held as a stepping stone or a stop gap may cause a general lack of interest in the job and may also dull perceptions on job demands as irritants rather than opportunities to learn. 


\subsection{Practical implications of the findings}

The redesign of work to create challenges for employees is an important practical consideration. On-the-job training should be included as it adds challenges and variety to work in making it more interesting. However, organisations should not focus too much on training as opposed to learning. Adults need to be responsible for their

own learning. Human resource development policy should provide the opportunities and allow employees to have significant input into deciding their own development and career paths.

\section{Conclusion}

Job-demand for learning, job-performance improvement initiatives and job-related learning are correlated. Job-performance improvement initiatives occur through the design of challenging jobs and enhance job-related learning.

\section{References}

Agyris, C. (1999) On Organizational Learning, 2nd ed., Cambridge, MA: Blackwell.

Antonacopoulou, E.P. and FitzGerald, L. (1996) 'Reframing competency in management', Human Resource Management Journal, Vol. 6, No. 1, pp.27-49.

Arthur, J.B. and Huntley, C.L. (2005) 'Ramping up the organizational learning curve: assessing the impact of deliberate learning on organizational performance under gain-sharing', Academy of Management Journal, Vol. 48, No. 6, pp.1159-1170.

Bandura, A. (1977) 'Self-efficacy: toward a unifying theory of behavioural change', Psychological Review, Vol. 84, pp.191-215.

Bhuiyan, N. and Baghel, A. (2005) 'An overview of continuous improvement: from the past to the present', Management Decision, Vol. 43, No. 5, pp.761-771.

Bierly III, P., Kessler, E. and Christensen, E. (2000) 'Organizational learning, knowledge and wisdom', Journal of Organizational Change Management, Vol. 13, No. 6, pp.595-618.

Boxall, P. and Purcell, J. (2003) Strategy and Human Resource Management, Basingstoke: Palgrave Macmillan.

Boyatzis, R. (1982) The Competent Manager: A Model for Effective Performance, New York, NY: John Wiley \& Sons.

Boydell, T. (1990) 'Modes of being and learning', Working Paper, Transform, Sheffield, No. 8.

Chin, W. (1998) 'The partial least squares approach for structural equation modeling', in G. Marcoulides (Ed.) Modern Methods for Business Research, Lawrence Erlbaum Associate, London, pp.295-336.

Delahaye, B.L. (2005) Human Resource Development: Adult Learning and Knowledge Management, Wiley: Sydney.

Devisch, M. (1998) 'The Kioto people management model', Total Quality Management, Vol. 9, Nos. 4-5, pp.62-65.

Ellstrom, P.E. (2003) 'Developmental learning - a condition for organisational learning', in B. Nyhan, M. Kelleher, P. Cressey and R. Poell, (Eds.) Facing up to the Learning Organisation Challenge - Volume II: Selected European Writings, Cedefop Reference Series, Office for Official Publications of the European Communities, Luxembourg. 
Field, L. (1997) 'Impediments to empowerment and learning within organizations', The Learning Organization, Vol. 4, No. 4, pp.149-158.

Fornell, C. and Larcker, D. (1981) 'Evaluating structural equation models: LISREL and PLS applied to consumer-exit theory', Journal of Marketing Research, Vol. 19, pp.39-50.

Fried, Y. and Ferris, G.R. (1987) 'The validity of the job characteristics model: a review and meta-analysis', Personnel Psychology, Vol. 40, pp.287-322.

Fry, R. and Kolb, D. (1979) 'Experiential learning theory and learning experiences in liberal arts education', New Directions for Experiential Learning, Vol. 6, pp.79-92.

Furth, H.G. (1987) Knowledge as Desire, New York, NY: Columbia University Press.

Gagne, R., Briggs, L. and Wager, W. (2002) Principles of Instructional Design, 5th ed., New York: Holt, Rinehart and Winston.

Garavan, T.N. (1991) 'Strategic human resource development', Journal of European Industrial Training, Vol. 15, No. 1, pp.17-30.

Hackman, J. and Oldham, G. (1980) Work Redesign, Reading, MA: Addison-Wesley.

Hair, J., Anderson, R., Tatham, R. and Black, W. (1998) Multivariate Data Analysis, NJ: Prentice Hall.

Illeris, K. (2003) 'Workplace learning and learning theory', Journal of Workplace Learning, Vol. 15, No. 4, pp.167-178.

Lahey, B. (2004) Psychology: An Introduction, 8th ed., NY: McGraw Hill.

Loogma, K. (2003) 'Learning at work and competence: different contexts and meanings in the case of transition economy', Journal of European Industrial Training, Vol. 28, No. 7, pp.574-586.

Nyhan, B., Cressey, P., Tomassini, M., Kelleher, M. and Poell, R. (2004) 'European perspectives on the learning organization', Journal of European Industrial Training, Vol. 28, No. 1, pp.67-92.

Orpen, C. (1997) 'The effects of formal mentoring on employee work motivation, organizational commitment and job performance', The Learning Organisation, Vol. 4, No. 2, pp.53-60.

Simonin, B.L. (1997) 'The importance of collaborative know-how: an empirical test of the learning organization', Academy of Management Journal, Vol. 40, No. 5, pp.1150-1174.

Sims, R. (1983) 'Kolb's experiential learning theory: a framework for assessing person-job interaction', The Academy of Management Review, Vol. 8, pp.501-508.

Spreitzer, G. (1995) 'Psychological empowerment in the workplace dimensions, measurement and validation', Academy of Management Journal, Vol. 38, pp.1442-1456.

Torrington, D. and Hall, L. (1998) Human Resource Management, 4th ed., Italy: Prentice Hall.

Van der Heijden, B. (2001) 'Encouraging professional development in small and medium-sized firms: the influence of career history and job content', Career Development International, Vol. 6, No. 3, pp.156-168.

Van der Sluis-den Dikken, L. and Hoeksema, L. (2001) 'The palette of management development', Journal of Management Development, Vol. 20, No. 2, pp.168-179.

Van Woerkom, M. (2003) Critical Reflection at Work: Bridging Individual and Organisational Learning, The Netherlands: Twente University Publications.

Vincent, A. and Ross, D. (2001) 'Personalize training', The Learning Organization, Vol. 8, No. 1, pp.36-43. 


\section{Appendix Items used for the variables}

Job-demand for learning

JDL1: My job is very dynamic, changing rapidly (e.g., technical, roles, duties).

JDL2: My job is getting increasingly complex, due to a rising number of tasks and responsibilities.

JDL3: My job is changing all the time.

\section{Job performance improvement initiatives}

JPII1: In the last six months, I have actively sought better ways to perform my job.

JPII2: In the last six months, I have actively sought new ways to perform my job.

\section{Job-related learning}

JRL1: In the last six months, I have acquired a lot of new job-related knowledge.

JRL2: In the last six months, I have learnt a lot of things that have helped me to perform my job better.

JRL3: In the last six months, I have acquired a lot of new job-related skills. 